\title{
Influence of Career Self-Efficacy Beliefs on Career Exploration Behaviours among TVET College Students in Wollega Zones Town
}

\author{
Getu Tadele* and Enkosa Terefe \\ Department of Behavioural Science, College of Education and Behavioural Science, Wollega University, \\ Post Box No: 395, Nekemte, Ethiopia
}

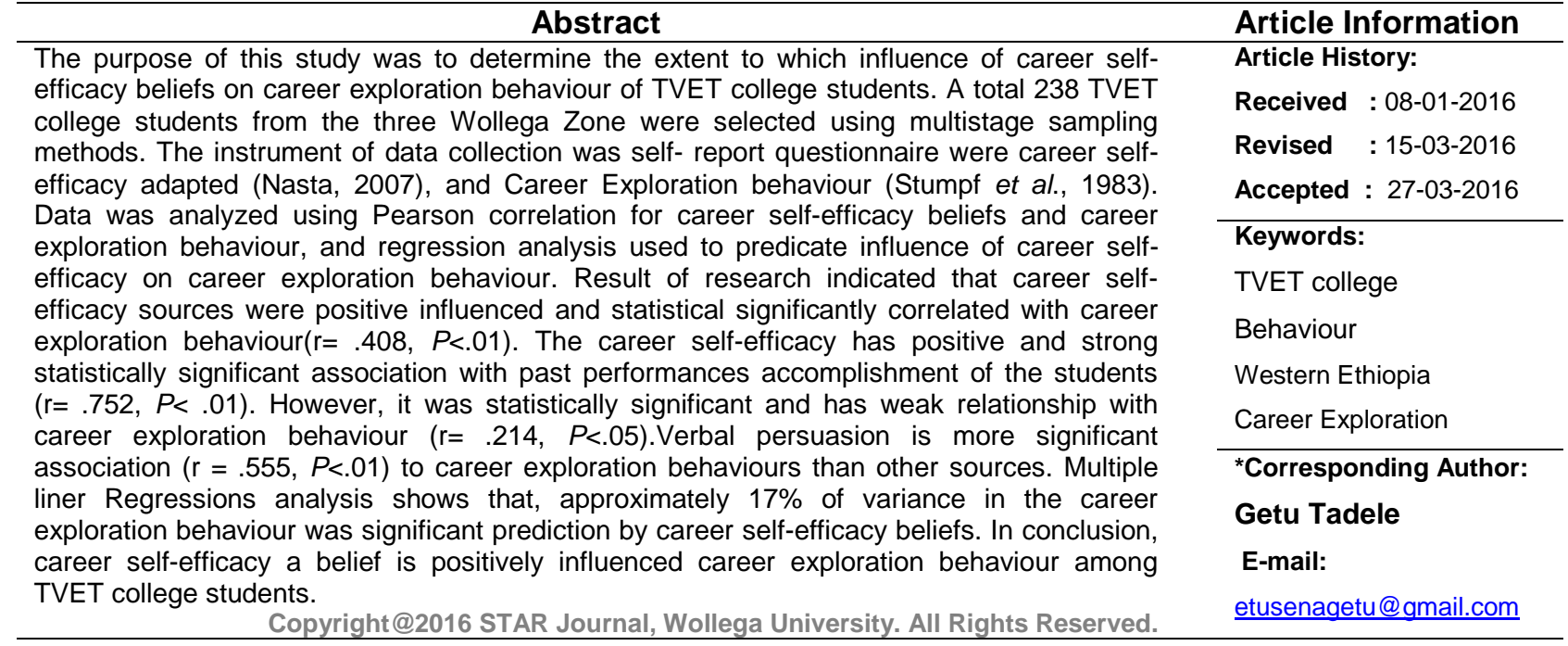

\section{INTRODUCTION}

A career is a pattern of work experiences comprising the entire life span of a person and which is general seen with regard to a phases or stages reflecting the transition from one stage of life to the next (Weinert, 2001). Similarly, career is as the combination and sequence of work roles that a person experiences throughout their lifetime (Super, 1980). The term career is the sequence of interaction of individuals with societies, education and organizations (Beukes, 2009; Herr et al., 2004).

Career exploration refers to all of the activities that individuals engage in for the purpose of promoting career development, choice, or adjustment. Participation in exploratory activities promotes an understanding of self and the environment that enables people to develop realistic career goals and plans (Sugalski and Greenhaus, 1986). Although career exploration occurs at all ages and stages of development (Sharf, 2006). Stumpf et al. (1983) developed a model of career exploration that involves exploration process reactions to exploratory behaviours and exploration beliefs. This model suggests that interact in a reciprocal manner, resulting in unique exploration experiences for each individual (Bartley and Robitschek, 2000).
It is perceived however, that only through systematic and thorough career exploration can people adequately gather information that will help them make clear and successful career choices (Atkinson and Murrell, 1988). Nesdale and Pinter (2000) found in their study that as opposed to not participating in these activities, when people seek employment through job training, preparing resumes, answering advertisements, and interviewing, it increases their probability of obtaining employment. It is important then that career exploration has proper structure and involves various types of career seeking activities to find employment.

However, Self-efficacy is an individual's level of confidence in and beliefs about his/her capabilities to successfully carry out courses of action, perform given behaviours, accomplish given tasks, and attain desired performance outcomes (Bandura, 1997 and Betz and Taylor, 2001). Self-efficacy can ultimately determine whether an individual will choose to perform or refrain from performing a task (Bandura, 1982). In fact, people's beliefs about their capabilities are often central to how they interact with the world (Sterrett, 1998). 


\section{Getu Tadele and Enkosa Terefe}

It is believed that self-efficacy beliefs influence how people feel, think, motivate them, and behave (Bandura, 1993). In Bandura's (1986) model of social learning, he describes self-efficacy as a cognitive structure created by the cumulative learning experiences in a person's life. People who have high self-efficacy are more likely to attempt and successfully execute tasks, whereas those with low self-efficacy find it difficult to achieve them because they are often fighting self doubt (Bandura, 1993 and 1997).

According to Bandura's (1977 and 1982) self-efficacy theory proposed that self-efficacy beliefs are developed and increased primarily through four major processes and sources of information. These components help individuals determine if they believe they have the capability to accomplish specific tasks. These sources are truly essential in understanding how self-efficacy beliefs develop, and are the foundation for the current research.

\section{Past Performance Accomplishments}

Self-efficacy is flexible, it usually comes from sources that are based primarily on past performance experiences (Lane, Jones and Stevens, 2002). In fact, past performance accomplishments tend to be the most powerful and dependable predictors of self-efficacy beliefs (Bandura, 1977, 1986; Dawes, Horan, and Hackett, 2000; Lane et al., 2002). Research evidence showed that high self-efficacy beliefs from experiences of success and mastery, and low self-efficacy based on poor experiences also generalize across different contexts and situations (Lane et al., 2002; Niles and Sowa, 1992; Sterrett, 1998). However, Brown (2002) explained that outcome expectations are personal beliefs about the consequences or outcomes of performing particular behaviours. Whereas self-efficacy beliefs are concerned with one's capabilities (Can I do this?), outcome expectations involve the imagined consequences of performing given behaviours. Outcome expectations include several types of beliefs about response outcomes, such as beliefs about extrinsic reinforcement, self directed consequences, and outcomes derived from the process of performing a given activity.

\section{Verbal Persuasion}

According to Redmond (2010), self-efficacy is influenced by encouragement and discouragement pertaining to an individual's performance or ability to perform, such as a manager telling an employee: "You can do it. I have confidence in you." Using verbal persuasion in a positive light generally leads individuals to put forth more effort; therefore, they have a greater chance at succeeding. However, if the verbal persuasion is negative, such as a manager saying to the employee, "This is unacceptable! I thought you could handle this project" can lead to doubts about oneself resulting in lower chances of success. On the other hand, a person's self-efficacy can also be increased when encouraged by others they are capable of successfully completing a task, especially regarding mastery in difficult situations (Bandura, 1977). Guidance and positive suggestions from others can assist in correcting performance in areas needing improvement, which are producing unsuccessful results. This encouragement however, can be less influential than an individual's own accomplishment experiences, since it is not based on authentic personal experiences (Bandura, 1977). As a result, a person may not truly believe what they are being told. In response, it is important that people utilize verbal support and

\section{Sci. Technol. Arts Res. J., Jan-March 2016, 5(1): 108-114}

encouragement from others, to be motivated to create new opportunities to observe their own success.

\section{Emotional Arousal}

Emotional arousal is another source of information that can influence self-efficacy (Bandura, 1977). People often rely to some extent on their emotional reactions to situations or tasks to help determine if they can cope and be successful at it (Bandura, 1977). High negative emotional arousal often debilitates performance, whereas positive emotional arousal can raise performance (Bandura, 1977). Negative emotional arousals are stressful reactions that often lead to fear, and cause people to doubt their competency (Bandura, 1977). Positive emotional arousals and anxiety towards a task can lead people to be more motivated to perform successfully and increase feelings of satisfaction from the task. It is essential therefore, that techniques to reduce negative and increase positive emotions be used to raise self-efficacy.

\section{Vicarious Learning}

Observing others perform successfully can improve people's beliefs in their own capabilities to perform in similar ways, and helps encourage persistence in their own efforts (Bandura, 1977). People often compare themselves to others and become convinced that if someone else similar to them can do it, so can they. The clearer the outcomes and the more determination expended in the face of obstacles by the model, the more likely the observer will be to model that behaviour in the future (Bandura, 1977). As a result, it is beneficial for people to observe the successes of others to help enhance their confidence in their own abilities to succeed. These sources are truly essential in understanding how self-efficacy beliefs develop, and are the foundation for the current research.

To date, no studies have focused specifically on the influence of career exploration process behaviours on the level of career certainty. However, in one study, Mako (1990) examined the relations among career exploration, career indecision, narcissism, and egocentrism. One of the central findings was that career certainty correlated positively with Environmental Exploration $(r=0.18)$, SelfExploration $(r=0.17)$, and Internal Search Instrumentality $(r=0.15)$. Mako concluded that as the amount of certainty about a major or career decision increased, the amount of self and environmental exploration and beliefs in the value of self-examination and reflection also increased. Sterrett (1998), just the basic career self-efficacy belief that one can successfully search for a job is need for initiating the job search, obtaining employment, enduring rejection, and staying with a job once, it is obtained. Similarly, Van Ryn and Vinokur (1992) found that the higher an individual's level of career self-efficacy, the more job search behaviours and positive employment outcomes would occur. Yet, career exploration behaviour is the major student's job search problem that is under recognized as public burden. Therefore, the present study will assess career self-efficacy belief and career exploration behaviour Technical and Vocational education training college (TVET) in three zones namely (TVET college in Nekemte, West Wollega and Horo Guduru Zones Town).

Lack of self-confidence can lead to career decisionmaking paralysation and a further lower of self-esteem (Nota and Soresi, 2003). Self-efficacy beliefs inform not 


\section{Getu Tadele and Enkosa Terefe}

only the range of occupations individuals perceive as viable career options, but influence the level of persistence and success that individuals have in their chosen career fields (Hackett and Betz, 1981). To date, no studies have focused specifically on the influences of career self-efficacy on career exploration behaviour among TVET students. The focus of most studies can be categorized primarily into the areas of career choice (Esters and Bowen, 2005; Jones and Larke, 2001; Scofield, 1994), career perceptions ( Hoover and Houser, 1991; Thompson and Russell, 1993; White, Stewart, and Linhardt, 1991), career decision making (Kotrlik and Harrison, 1989), and college choices Conrad et al., 2004).

However, there has been no research focused on antecedents of career choice, such as career exploration throughout the career development process (Blustein and Phillips, 1988; sugalski and Greenhaus, 1986). Given that there has been no research conducted on the influence of career self-efficacy on career exploration behaviour among TVET college students, the present study was conducted to address this void by exploration these constructs with a group of postsecondary TVET students. In fact, relationship career self-efficacy and career exploration behaviour is unique Technical and Vocational Education and Training. Because lack of organized information, lack of confidence, lack of vicarious selfefficacy, lack modelling, job search, create jobs, awareness of students, very limited career search area career exploration behaviours in Ethiopia. The objective of the study was to assess career self-efficacy influences on career exploration behaviour among TVET college students in three-Wollega zones town.

\section{MATERIALS AND METHODS}

\section{Research Design}

Descriptive and Correlational survey design was employ to investigate the relationships career self-efficacy beliefs and career exploration behaviour among Technical and Vocational Education Training (TVET) college students in three towns namely; Gimbi TVET, Nekemte TVET and Shambu TVET.

\section{Population and sampling Techniques}

Population of the study was TVET college students in Wollega zones town and consists of 238 of male (113) female (184) TVET college students. The study was applying multi-stage sampling procedure since there are diversified respondents in terms location/ residence and grade level. The researcher was use-sampling methods to select respondents. First the researcher were use purposively sampling techniques to select study area because based on catchment area of Wollega University and also more facilitate and trains students up to level $V$ were selected. The grade level students attends II and above are included but researcher excluded level I college students because the students accomplishment unknown. The second, the researcher also use stratified sampling methods was select department and grade/level. Finally, the researcher was use systematic random sampling methods for selection of students.

\section{Instrument of Data Collection}

The survey consisted of three measures constructed to assess close-ended questionnaires demographic, sources of career self-efficacy belief and career exploration behaviour. First, Questionnaires were use to collect demographic data including gender, age, and year
Sci. Technol. Arts Res. J., Jan-March 2016, 5(1): 108-114

in training, and college major category. Secondly, to measure the sources of career self-efficacy beliefs, the Career Self-Efficacy Sources Scale was adapted from Nasta, (2007). The Career Self-Efficacy Sources Scale is based on Bandura's (1977) four sources of self-efficacy information. It measures an individual's self-efficacy towards obtaining a job, and consists of 20 questions total. The responses were scored on an interval Likert Scale (1-5), with responses (1) Never (2) Rarely (3) Sometimes (4) Often (5) Very Often.

The third, measure career exploration behaviour a revised version of the Career Exploration Survey adapted from (Stumpf et al., 1983) called the Career Exploration Survey-Revised (CES-R). The Career Exploration SurveyRevised consists of 28 questions. Responses were scored on an interval Likert-type scale. The scales responses were (1) Never (2) Somewhat (3) A Moderate Amount (4) A Substantial Amount (5) A Great Deal.

\section{Procedure of Data Collection}

The procedure of data collection, first the researchers contacted the representative of three TVET colleges and got permission to conduct the study. After getting cooperative responses from college and some teacher, the researcher contacted their TVET College to make the research legal. Those colleges permitted the researcher to arrange with the research to devote one period (50 minutes). Second, based on the arrangement made, the researcher contacted the students with the teachers of the college and the researcher explained the objectives of the study for the students and assured them about the confidentiality of their responses. Students did not provide their names and were not asked any other personal identification. The students were instructed to finish the questionnaire in the class within the 50 min class meeting and return the questionnaire to their classroom teachers or researcher before they left the class. Though these procedures therefore the item were administered and data collected.

\section{Data Analysis}

After the necessary data was collect and coded, statistical tests were perform using the Statistical Package for Social Sciences (SPSS) for Window, version 20. Statistical methods including descriptive statistics, Pearson correlation, Regression, and variances were use in the analysis. Descriptive statistics was use for the analysis of the basic demographics and survey items of the questionnaire; Pearson correlation was compute to determine the association of the variables of the study (sources of career self-efficacy and career exploration behavior) between them. In addition to analysis, multiple Regression analysis was used to test which source has the strongest influences.

\section{RESULTS}

In this part, the results of the study are present in tables and with statistical descriptions, which show statistically significances and non-significant relations among the variables.

\section{Demographics Characteristics}

As it is indicate table 1 , out of the 300 participant, 62 responses were discarded due to incomplete filled-out questionnaire and responses and 238 students of Technical and vocational Education training (TVET) was correctly responded. The number of males in the current 


\section{Getu Tadele and Enkosa Terefe}

study was $113(47.48 \%)$ and females $125(52.52 \%)$. The ages of the students range from $16-21(77.31 \%)$ and 22 $30(22.69 \%)$ years.

Table1: Characteristic of the Participants $(n=238)$

\begin{tabular}{cccc}
\hline Variable & Categories & Frequency & \% \\
\hline \multirow{3}{*}{ Sex } & Male & 113 & 47.48 \\
& Female & 125 & 52.52 \\
\cline { 2 - 4 } & Total & $\mathbf{2 3 8}$ & $\mathbf{1 0 0}$ \\
\hline \multirow{3}{*}{ Age } & $16-21$ & 184 & 77.31 \\
& $22-30$ & 54 & 22.69 \\
\cline { 2 - 4 } & Total & $\mathbf{2 3 8}$ & $\mathbf{1 0 0}$ \\
\hline \multirow{4}{*}{ Level of } & Level II & 82 & 34.45 \\
Year & Level III & 79 & 33.19 \\
& Level IV & $\mathbf{7 7}$ & 32.35 \\
\cline { 2 - 4 } & Total & $\mathbf{2 3 8}$ & $\mathbf{1 0 0}$ \\
\hline
\end{tabular}

\section{Results Obtained using Descriptive Statistics} Descriptive Statistics

Based on table2, the mean of career self-efficacy beliefs $(M=55.46$; $S D=9.39)$ while career exploration behaviour $(\mathrm{M}=86.33$; $\mathrm{SD}=22.31)$. The highest sources self-efficacy beliefs vicarious learning $(M=12 ; S D=3.89$; verbal persuasions $(M=11.98 ; S D=3.96)$ and followed by emotional arousal $(M=10.46 ; S D=2.71)$.

Table 2: Mean and Standard Deviation Scores for Participant Responses on Career Scales $(n=238)$

\begin{tabular}{lcl}
\hline Scale Responses & Mean & SD \\
\hline Vicarious Learning & 12.00 & 3.89 \\
Verbal Persuasion & 11.98 & 3.96 \\
Emotional Arousal Positive & 10.56 & 2.76 \\
Emotional Arousal Negative & 10.39 & 2.66 \\
Performance Accomplishments & 10.53 & 2.88 \\
Career Self-Efficacy & 55.46 & 9.39 \\
Career Exploration & 86.33 & 22.31 \\
\hline
\end{tabular}

Sci. Technol. Arts Res. J., Jan-March 2016, 5(1): 108-114

Relationship between Sources of Career Self-Efficacy Belief and Career Exploration Behaviours

Table 3, Results showed that career self-efficacy is significantly positively correlated with career exploration behaviours $(r=0.408, P<0.01)$. The source of career selfefficacy were moderate positive associate with career exploration behaviour, Vicarious learning $(r=0.383, P<$ $0.01)$, verbal persuasion $(r=0.555, P<0.01)$, emotional arousal positive ( $r=0.371, P<0.01)$, emotional arousal negative $\quad(r=-0.349, \quad P<0.01)$ and performance accomplishments $(r=0.214, P<0.05)$.

\section{Relationship between Sources of Career Self-Efficacy and Self-efficacy}

Pearson correlation between the study variables, including the univariate associations between the career self-efficacy beliefs, sources of career self-efficacy and career exploration behaviour (Table3). College Students scores on career self-efficacy and career explorations were moderate and positively correlated. For the showed that regarding career self-efficacy significant relationship with sources of self-efficacy vicarious learning $(r=0.351$, $P<0.01)$, verbal persuasion $(r=0.360, P<0.01)$, emotional arousal positive $(r=0.585, P<0.01)$, emotional aroused negative correlated ( $r=0.618)$. In addition past performance accomplishment they were strong and positively correlated with career self-efficacy $(r=0.752, P$ $<0.01$ ). On the other hand vicarious learning strong and positive significant correlated with verbal persuasion ( $r=$ $0.579, \quad P<0.01)$ and performance accomplishments significantly correlated with emotional arousal positive ( $r=$ $0.308, P<0.01)$, but emotional arousal negative and weak relationship $(r=0.221, P<0.05)$.

Generally, career self-efficacy were significantly correlated with career exploration behaviour $(r=0.408$, $P<0.01)$ and sources of self-efficacy positive correlated and significant with career exploration behaviour. Furthermore, verbal persuasion and Vicarious learning are first and second more significant relationship with career exploration than other sources of career selfefficacy $\left(r=0.555^{\star \star}, \quad P<0.01, \quad r=0.383^{\star *}, \quad P<0.01\right)$ respectively. However, past performance accomplishments were the weak, but significant relationship with career exploration behaviour.

Table 3: Pearson Correlations between Career Self-Efficacy, Career Exploration, and Sources of Career Self-Efficacy. $(n=238)$

\begin{tabular}{|c|c|c|c|c|c|c|c|c|}
\hline & Variables & 1 & 2 & 3 & 4 & 5 & 6 & 7 \\
\hline 1 & Career Self-Efficacy & - & & & & & & \\
\hline 2 & Career Exploration & $.408^{\star *}$ & & & & & & \\
\hline 3 & Vicarious Learning & $.351^{\star \star}$ & $.383^{\star *}$ & & & & & \\
\hline 4 & Verbal Persuasion & $.360 * *$ & $.555^{\star \star}$ & $.579 \star \star$ & & & & \\
\hline 5 & Emotional Arousal Positive & $.585^{\star \star}$ & $.371^{\star \star}$ & .046 & -.019 & & & \\
\hline 6 & Emotional Arousal Negative & $.618^{\star}$ & $.349 * \star$ & $.221^{\star}$ & $.334^{\star \star}$ & .135 & & \\
\hline 7 & Performance Accomplishments & $.752^{\star}$ & $.214^{\star}$ & .022 & $.144^{\star}$ & $.391^{\star \star}$ & $.338^{\star *}$ & - \\
\hline
\end{tabular}

Generally, Person correlation between the career selfefficacy and career exploration behaviour were positive and moderate correlated. Moreover, the relationship between Performance accomplishments and Career selfefficacy was positively and strong correlate, but association between past performance accomplishment were positive association with career exploration behaviours. In above table indicated that career selfefficacy were strong significant correlated with performance accomplishment than career exploration. 


\section{Getu Tadele and Enkosa Terefe}

Next, we employed regression analysis was explore to see how well scale score from the career self-efficacy predicted scores on the career exploration behaviour score which of CSE scales were the most useful in this regard. The predictors were the career self-efficacy, and the criterion was the respondent's score. The liner regression combination of career self-efficacy was significantly positive related to career exploration behaviour, $F(4,841)=20.029, P<.05$. The sample multiple
Sci. Technol. Arts Res. J., Jan-March 2016, 5(1): 108-114

correlation coefficient was 0.408 , indicating that approximately $17 \%$ of variance of career exploration behaviour for this sample were accounted for by the linear combination of the career self-efficacy. As can seen in table 4, the career self-efficacy beliefs and career exploration behaviour scales had significant positive regression weight, indicating students with higher career self-efficacy on these scales were expected to have higher career exploration behaviour.

Table 4: Summary Table of Multiple Leaner Regression Analysis for Sources of Career Self-Efficacy Variables and Career Self-Efficacy in Predicting Career Exploration $(\mathrm{N}=238)$

\begin{tabular}{lcccc}
\hline Variables & B & Std. error & Beta & t \\
\hline Career self-efficacy & .677 & .151 & $.408^{*}$ & 4.475 \\
Vicarious Learning & .451 & .498 & .092 & .906 \\
Verbal Persuasion & .751 & .560 & $.502^{*}$ & .914 \\
Emotional arousal positive & .482 & .199 & $.379^{*}$ & .571 \\
Emotional arousal Negative & .409 & .258 & .126 & .584 \\
Performance Accomplishment & -.407 & .445 & -.081 & -.914 \\
\hline \multicolumn{4}{c}{ *. Correlation is significant at the 0.05 level (2-tailed) }
\end{tabular}

Career Exploration Vs Sources of Career Self-efficacy

To examine whether the sources of career self-efficacy explained variances occurs career self-efficacy, a multiple linear regression analysis was performed. The predictor variables were the five sources of career self-efficacy and career self-efficacy, and the criteria variable was career exploration.

As can seen in Variance, indicated that regression models career exploration on the sources career selfefficacy revealed the models significantly increased the predicting verbal persuasion $\mathrm{F}(4,553)=22.646, P<0.05$ of variance accounted $30 \%$ and Emotional arousal positive $F(4,414)=27.436, P<0.05$ in which $39.5 \%$ of the variance accounted in career exploration behaviour. On the other hand, vicarious learning and emotional arousal negative are did not significant and influences in career exploration behaviour. Performance accomplishment was not found to be significant $F(2,754)=17.356, P<0.05$. It seems that previous performance accomplishment did not have an impact on the overall relationship between career selfefficacy.

A Multiple regression analysis results indicated that only two were significant predicting relation to verbal persuasion and emotional arousal positive with career exploration behaviour. Nevertheless, performance accomplishment was not predicting variable, but positive correlated and not significant with career exploration behaviour.

\section{DISCUSSION}

The aims of this descriptive survey were to assess the influence of the sources of career self-efficacy beliefs on career exploration behaviours. The current studies indicate that the career self-efficacy beliefs do have moderate and positive influence on career exploration behaviours $(r=0.408, P<0.01) \mathrm{F}(4,841)=20.029, P<$ 0.01 , in which approximately $17 \%$ of variance. Past research is consistently support to regressing career selfefficacy on the sources revealed that overall the model significantly predicted career self-efficacy, $F(1,257)=$ $56.75, P<0.001$, in which $18 \%$ of variance (Nasta, 2007). Career self-efficacy was account for by the source Career self-efficacy has also been found to be one of the best predictors of many beginning career behaviours, such as job searching (Niles and Sowa, 1992). In addition, research has found that career self-efficacy beliefs do indeed have a strong influence on career exploration and employment outcomes. Past studies support then, that career self-efficacy beliefs can in fact influence career exploration behaviours.

Regarding, the relationship between career selfefficacy and career exploration behaviour, result of current research show that career self-efficacy and the sources of career self-efficacy beliefs significant correlated with and predict career exploration. These results are consistent with past research, which has also shown that a significant relationship exists between career self-efficacy and career exploration activities (Betz and Voyten, 1997; Blustein, 1989; Dawes et al., 2000; Foltz and Luzzo, 1998; Van Ryn and Vinokur, 1992).

\section{Relationship between Sources of Career self-efficacy} and Career Exploration Behaviours

The source of career self-efficacy were significant correlated with career exploration behaviour, Vicarious learning $(r=0.383, P<0.01)$ in table 3 predicting values is 13.8 percent of variance in career exploration behaviour. Past studies analogous with (Bandura, 1977), as a result, it is beneficial for people to observe the successes of others to help enhance their confidence in their own abilities to succeed. The clearer the outcomes and the more determination expended in the face of obstacles by the model, the more likely the observer will be to model that behaviour in the future. In addition to, verbal persuasion associated with career exploration behaviour is significant $(r=0.555, P<0.01)$ in which $30 \%$ of variance. Many studies show that, Guidance and positive suggestions from others can assist in correcting performance in areas needing improvement, which are producing unsuccessful results (Bandura, 1977). This encouragement however, can be less influential than an individual's own accomplishment experiences, since it is not based on authentic personal experiences. As a result, it is important that people utilize verbal support and 


\section{Getu Tadele and Enkosa Terefe}

encouragement from others, to be motivated to create new opportunities to observe their own success.

Regarding, emotional arousal significant correlation with career exploration behaviours positive $(r=0.371$, $P<0.01$ ) indicted that approximately 44 percent of variance and emotional arousal negative $(r=-0.349$, $P<0.01)$ in which $44.8 \%$ of variance account in career exploration behaviour. Past research consistence with emotional arousal is another source of information that can influence self-efficacy. People often rely to some extent on their emotional reactions to situations or tasks to help determine if they can cope and be successful at it (Bandura, 1977). High negative emotional arousal often debilitates performance, whereas positive emotional arousal can raise performance (Bandura, 1977). Negative emotional arousals are stressful reactions that often lead to fear, and cause people to doubt their competency (Bandura, 1977). Positive emotional arousals and anxiety towards a task can lead people to be more motivated to perform successfully and increase feelings of satisfaction from the task. It is essential therefore, that techniques to reduce negative and increase positive emotions be use to raise self-efficacy.

Furthermore, the relationship between performance accomplishments and career exploration behaviour were weak correlate $(r=0.214, \quad P<0.05)$ which in career exploration behaviours. Previous research inconsistence association with past performance accomplishments tend to be the most powerful and dependable predictors of selfefficacy beliefs (Bandura, 1977 and 1986; Dawes, Horan, and Hackett, 2000; Lane et al., 2002). Research evidence showed that high self-efficacy beliefs from experiences of success and mastery, (Lane et al., 2002; Niles and Sowa, 1992; Sterrett, 1998).

\section{CONCLUSIONS}

The result of this study shows that, the Career selfefficacy beliefs were positive and has statistically significant correlation with career exploration behaviour. Similarly, there were the verbal persuasion and emotional arousal positive which can positively influence on exploring career. Career self-efficacy beliefs has positive influence on career exploration behaviour among TVET college students. This shows that, College students have been previous experience, motivation/encouragement, modelling them toward career opportunities is highly increased to develop career choice, career development, career adjustment, etc.

It is also important that college students be assist in understanding and improving their career self-efficacy beliefs, and in effectively exploring compatible career options to help them in the complex process of career development, planning, and preparation. Verbal persuasion of career self-efficacy is strong and influences the individual's career exploration. This means, increasing encouragement, motivation, credibility, guidance and positive suggestion will be increased task performance and exploration of career. From sources of career selfefficacy beliefs past performance accomplishment was highly correlated with self-efficacy $(r=0.752, P<0.01)$. In addition, verbal persuasion and Vicarious learning has also significant relationship with career exploration behaviour than other sources of career self-efficacy; $\left(\mathrm{r}=0.555^{\star \star}, P<0.01, \mathrm{r}=0.383^{\star \star}, P<0.01\right)$ respectively.
Sci. Technol. Arts Res. J., Jan-March 2016, 5(1): 108-114

Based on the major findings of the study, the following recommended were forwarded:

- There are no counselling services in those selected TVET Colleges, where as they need special career choice, career exploration, career development, guidance and counselling services early. Thus, TVET Colleges should have to assign professional Counsellors on each of TVET Colleges in collaboration with Oromia Education Bureau/Zonal Education Bureau.

- Ministry of Education/Oromia Education Bureau/Zonal Education Bureau need to establish the career centre which can provide the students about career information, career exploration, career choice, career adjustment, and searching jobs.

- The study suggest that, future research is needed on the influence of the sources of career self-efficacy on job seeking among culturally diverse populations and different age groups.

\section{Conflict of Interest}

None declared.

\section{REFERENCES}

Anderson, S.L., and Betz, N.E. (2001). Sources of social selfefficacy expectations: their Measurement and relation to career development. Journal of Vocational Behaviour 58: 98-117.

Atkinson, G. Jr., and Murrell, P.H. (1988). Kolb is experiential learning theory: a meta-Model for career exploration. Journal of Counselling and Development 66: 374-377.

Bandura, A. (1997). Self-efficacy: the exercise of control. New York: W. H. Freeman.

Bandura, A. (1977). Self-efficacy: toward a unifying theory of behavioural change. Psychological Review 84: 191-215.

Bandura, A. (1986). Social foundations of thought and action: A social cognitive theory. Englewood Cliffs, NJ: PrenticeHall.

Bandura, A. (1997). Self-efficacy: The exercise of control. New York: W.H. Freeman and Company.

Bartley, D. F. and Robistschek, C. (2000). Career exploration: a multivariate analysis of predictors. Journal or Vocational Behaviour 56: 63-81.

Betz, N.E. (1992). Counselling uses of career self-efficacy theory. Career Development Quarterly 41: 22-27.

Betz, N. E. (1994). Self-concept theory in career development and counselling. Career Development Quarterly 43: 3243.

Betz, N.E. and Hackett, G. (1981). The relationship of careerrelated self-efficacy expectations to perceived career options in college women and men. Journal of Counselling Psychology 28: 399-410.

Betz, N. E. and Taylor, K.M. (2001). Manual for the career decision self-efficacy scale and CDMSE- Short Form.

Brown Duane. (2002). Career choice and development. Duane Brown and associates: fourth ed. (The JosseyBass business and management series)

Brown, C., Darden, E.E., Shelton, M.L. and Dipoto, M.C. (1999). Career exploration and self-efficacy of high school students: Are there urban/suburban differences? Journal of Career Assessment 7(3): 227-237. 


\section{Getu Tadele and Enkosa Terefe}

Esters, L.T. and Bowen, B.E. (2005). Factors influencing career choices of urban agricultural education students. Journal of Agricultural Education 46(2): 23-34.

Fortz, D.L. and Luzzo, S. D. (1992). Individual and contextual factors in career exploration. Journal of Vocational Behavior 33: 203-216.

Hackett, G. and Betz, E. (1981). A self-efficacy approach to the career development of Women. Journal of Vocational Behaviours 18: 326-339.

Jones, W.A. and Larke, A. (2001). Factors influencing career choice of African-American and Hispanic graduates of a land-grant college of agriculture. Journal of Agricultural Education 42(1): 38-48.

Lane, R. W., Brown, S. D., and Hackett, G. (1994). Toward social cognitive theory of Career and academic interest, choice, and performance. Journal of Vocational Behaviours 45: 79-122.

Mako, T.J. (1990). Relations among career exploration, career indecision, narcissism, and egocentrism. Upublished doctoral dissertation. Kent State University, Kent, Ohio.

Nasta A. Kristen (2007). Influence of Career Self-Efficacy Beliefs on Career Exploration Behaviors. Master of Science in Mental Health Counseling. The State University of New York. M.Sc Thesis.

Nesdale S.M and Pinter, M.U. (2000). Explorations of the career exploration literature: status and future directions. Paper presented at the meeting of the American Educational Research Association, Boston, MA.

Nile S. G., Saw H. (2004). Career Guidance and Counselling through the lifespan: systematic approaches. (6 $6^{\text {th }}$.edition). London: Prentice-Hall.

Scofield, G. (1994). An lowa study: Factors affecting agriculture student's career choice. NACTA Journal 38(4): 2830.

Sharf, R.S. (2006). Applying career development theory to counselling. ( $4^{\text {th }}$ Ed.). Belmont, CA: Thomson Wadsworth.
Sci. Technol. Arts Res. J., Jan-March 2016, 5(1): 108-114

Stumpf, S.A. (1992). Career exploration. In: L. Jones (Ed.), Encyclopaedia of career decision and work issues. (pp. 4445). Phoenix, AZ: Onyx Press.

Stumpf, S.A. and Lockhart, M.C. (1987). Career exploration: Work-role salience, work preferences, beliefs, and behaviour. Journal of Vocational Behaviours 30: 258-269.

Stumpf, S.A., Colarelli, S.M. and Hartmann, K. (1983). Development of the Career Exploration Survey (CES). Journal of Vocational Behaviour 22: 191-226.

Super, D.E. (1957). The psychology of career. New York: Harper Row.

Super, D.E. (1980). A life-span approach to career development. In: D. Brown and L. Brooks (Eds.), Career choice and development: Applying contemporary approaches to practice (pp. 11-20). San Francisco: Jossey-Bass.

Tayulr, D. L. (1989). The role of career exploration in the career decision-making of college students. Journal of College Student Development 30: 111-117.

Thompson, J.C. and Russell, E.B. (1993). Beliefs and intentions of counsellors, parents, and students regarding agriculture as a career choice. Journal of Agricultural Education 34(4): 55-63.

Weinert, A.B. (2001). Psychology of career development. International Encyclopaedia of the Social and Behavioural Sciences, Elsevier Science, 1471-1476.

Werbel, J.D. (2000). Relationships among career exploration, job search intensity, and job search effectiveness in graduating college students. Journal of Vocational Behaviours 57: 379-394.

White, C., Stewart, B.R. and Linhardt, R.E. (1991). Career opportunities in agriculture as perceived by inner city high school students. Journal of Agricultural Education 32(1): 11-18. 